Pablo Berdón-Prieto

Universidad de Valladolid

@ pablo.berdon@uva.es (iD 0000-0002-5279-4426

Jacobo Herrero-Izquierdo

Universidad de Valladolid

@ jacobo.herrero@uva.es (iD 0000-0001-5672-3505

Dra. Itziar Reguero-Sanz

Universidad de Valladolid

@ itziar.reguero@uva.es (iD 0000-0002-3274-1861

Dra. Virginia Martín-Jiménez

Universidad de Valladolid

@ virginia.martin@uva.es iD 0000-0002-7099-1060
- Recibido / Received 20 de octubre de 2020

- Aceptado / Acepted 3 de noviembre de 2020

- Páginas / Pages De la 53 a la 72

- ISSN: $1885-365 X$

\title{
Madrid ante la Covid-19. La opinión de los estudiantes de periodismo sobre la praxis mediática ${ }^{1}$
}

\section{Madrid faced with Covid-19. The opinion of journalism students about media praxis}

\section{RESUMEN:}

La primera ola de la pandemia de la Covid-19 asoló, entre los meses de marzo y julio de 2020, a toda España con Madrid como epicentro de los contagios y fallecidos. Pese al confinamiento general de la población impuesto el 14 de marzo de 2020 el periodismo informativo continuó como un servicio esencial desempeñando su habitual labor. Este nuevo paradigma global transformó los usos y las costumbres tanto de emisores como de receptores. Por todo ello, el objetivo principal de esta investigación es conocer la opinión del «periodismo de pandemia» de un colectivo específico mediatizado, con un perfil de prosumidor y que ha convivido con el peor escenario de la enfermedad en su primera ola: los estudiantes del Grado en Periodismo de las universidades madrileñas. El método de análisis se basa en una encuesta de opinión cuyos resultados nos muestran cómo el consumo informativo de este grupo se centralizó casi en exclusiva en los medios digitales y las redes sociales. Además, el presente estudio revela que los encuestados se muestran críticos con la veracidad de las noticias y la existencia de fake news y se comprueba el problema

1/ Esta investigación es resultado del proyecto «Politainment en el entorno de la posverdad: nuevas narrativas, clickbait y gamificación» (Ref. CSO2017-84472-R, financiado por el Ministerio de Economía y Competitividad (Gobierno de España). 
de la sobreabundancia informativa acerca de la pandemia, lo que se ha conceptualizado como infodemia. Por último, se observa un escaso nivel de alfabetización mediática de los estudiantes, así como una falta de mecanismos para sortear las amenazas del periodismo en la era de la posverdad.

\section{PALABRAS CLAVE:}

Covid-19; Periodismo; Universidad; Madrid; Encuesta.

\section{ABSTRACT:}

The Covid-19 pandemic has devastated all of Spain with Madrid as the epicenter of infections and deaths. Despite the general confinement of the population, news journalism continued as an essential service, carrying out its usual work. This new global paradigm has transformed the uses and customs of both emitters and receivers. For all these reasons, the main objective of this investigation is to know the opinion of «pandemic journalism» of a specific media group, with a prosumer profile and who has lived with the worst scenario of the disease: the students of the Journalism Degree of Madrid universities. The method of analysis is based on an opinion poll, the results of which show how the consumption of information by this group has been almost exclusively centralized in digital media and social networks. In addition, the present study reveals that the respondents are critical of the veracity of the news and the existence of fake news and the problem of the overabundance of information about the pandemic is verified, which has already been conceptualized as an infodemic. Finally, there is a low level of student media literacy, as well as a lack of mechanisms to overcome the threats of journalism in the post-truth era.

KEY WORDS:

Covid-19; Journalism; University; Madrid; Survey.

\section{Introducción y objetivos}

El Gobierno de España decretó el Estado de alarma para todo el territorio nacional del 14 de marzo al 21 de junio de 2020 ante la situación provocada por el SARS-CoV-2. Su entrada en vigor, anunciada por el presidente Pedro Sánchez tras una reunión del Consejo de Ministros, implicó la reducción inmediata de ciertas actividades, salvedad de aquellos servicios considerados como "esenciales» que encararon la nueva situación sumidos en un contexto de gran incertidumbre. Dentro de estos últimos, se encontraban los medios de comunicación, que asumieron la difícil tarea de informar en medio de un panorama confuso y donde los datos sobre la enfermedad aumentaban de manera diaria.

Así pues, el periodismo continuó con su labor informativa, desplegando el rol social que se le atribuye (Casero-Ripollés, 2020²; Lázaro-Rodríguez y Herrera-Viedma, 2020³), además de su función democrática de informar y construir opinión (Kovach y Rosenstiel, 2007; Ha-

2/ Casero-Ripollés analizó, a través del panel de tendencias del Pew Research Center, cómo los estadounidenses modelaron su consumo de medios desde octubre de 2019 hasta marzo de 2020, momento en el que comenzó a aumentar la relevancia de la crisis de la Covid-19. Este autor considera que la aparición de esta nueva enfermedad ha servido a los medios noticiosos para reenganchar a usuarios antiguos que ya no consumían información provocando la llegada de un nuevo escenario cargado de complejidad e incógnitas.

3/ Los investigadores Pedro Lázaro-Rodríguez y Enrique Herrera-Viedma decidieron centrarse en cómo este nuevo paradigma surgido por el SARS-CoV-2 había sido asumido por los medios españoles y qué alteraciones se observaban en su producción informativa. Para ello, llevaron a cabo un estudio cuantitativo longitudinal en el que observaron cómo los medios digitales habían realizado las mayores alteraciones productivas. Los propios autores consideran a su estudio como un «punto de partida» para otros estudios con mayor profundidad de análisis. 
bermas, 2006). Sin embargo, y pese a ese reconocimiento de esencialidad, su trabajo llegó a cuestionarse hasta el punto de que el Centro de Investigaciones Sociológicas (CIS) incluyó, en el avance del barómetro del 15 de abril, el siguiente interrogante:

¿Cree Ud. que en estos momentos habría que prohibir la difusión de bulos e informaciones engañosas y poco fundamentadas por las redes y los medios de comunicación social, remitiendo toda la información sobre la pandemia a fuentes oficiales, o cree que hay que mantener libertad total para la difusión de noticias e informaciones? (CIS, 2020, pregunta 6).

La pregunta, que obtuvo un apoyo del $66,7 \%$ de la población, abrió un debate sobre el papel que debían desempeñar los medios de comunicación en una situación de emergencia como la determinada por el coronavirus y planteó como necesaria la revisión de la situación actual del periodismo, sus fortalezas, amenazas y retos futuros. La investigación que aquí se presenta ha intentado aportar respuestas y lo ha hecho a través de un objetivo principal: conocer la opinión de un sector específico de la población, los estudiantes del Grado en Periodismo, considerados prosumidores especiales por su formación y por el impacto que las informaciones podían causar en su desarrollo profesional. Para dar luz sobre estas cuestiones se han planteado una serie de hipótesis y subhipótesis:

- H1: La preocupación directa y personal de los estudiantes de periodismo por la pandemia ha sido el factor principal que ha promovido el aumento o disminución del consumo mediático.

- SH1: La situación de confinamiento generalizado ha provocado en los estudiantes de periodismo un consumo televisivo superior al de los medios online.

- H2: La crítica hacia el papel del periodismo durante la pandemia ha aumentado a medida que los estudiantes han estado más familiarizados con la profesión tanto a nivel de conocimientos (cursos más altos) como laboral (realización de prácticas).

- SH2: Las fake news han afectado en mayor medida a los cursos más bajos de los estudiantes de periodismo.

Más en concreto, este trabajo se ha centrado en el alumnado de periodismo de la Comunidad de Madrid, al ser este territorio el más afectado por la Covid-19 en la primera ola pandémica, con más de 8.400 víctimas mortales y cifras superiores a los 72.000 contagiados a fecha de 3 de julio (Ministerio de Sanidad, 2020). En pleno confinamiento (19-23 de abril), Madrid ya despuntaba tanto a nivel nacional, acaparando más de un $28 \%$ de los contagiados de España, como a nivel europeo, equiparándose a regiones como Lombardía -tal y como se observa en la figura 1- donde el virus había golpeado fuerte desde su llegada al viejo continente. De igual modo, el Estudio Nacional de sero-epidemiología (ENE-Covid) llevado a cabo por el Instituto de Salud Carlos III a fecha de 3 de junio también reconoció a Madrid como una de las Comunidades con un mayor número de personas que habían desarrollado anticuerpos; más de un $11 \%$ de su población (Pollán et al., 2020). 


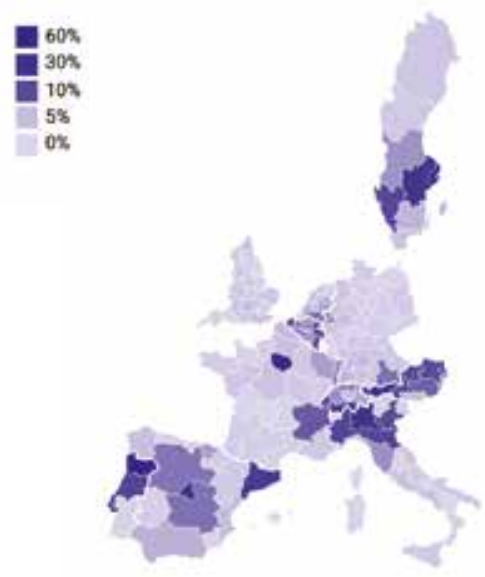

Figura 1. Las principales regiones contagiadas de cada país. Distribución de los casos de cada Comunidad Autónoma (y equivalentes) respecto al total de cada país. Fuente: www.elconfidencial.com a partir de datos oficiales

En la comunidad madrileña, además, se concentraban, según las estadísticas oficiales del Sistema Integrado de Información Universitaria (SIIU), hasta 8.135 alumnos de Periodismo distribuidos en las diez universidades (tres públicas y siete privadas) ${ }^{4}$; cifra que representa un $43,15 \%$ del total de matriculados a nivel nacional (Ministerio de Ciencia, Innovación y Universidades, 2019). Este doble aliciente, el alto grado de afectación del virus y el elevado número de miembros de la titulación, explica el motivo de poner el foco en dicha región, que otorga al estudio una visión no poco representativa.

Pese a la reciente aparición de la Covid-19, son varias las investigaciones que han abordado el papel de los medios en este contexto: desde una perspectiva cuantitativa (LázaroRodríguez y Herrera-Viedma, 2020); desde la óptica del consumo y de la credibilidad mediática (Casero-Ripollés, 2020); de la comunicación corporativa (Xifra, 20205); de la economía (Odriozola-Chené et al., 2020) o de la manera en la que se ha informado a través de

4/ Universidad Complutense de Madrid, Universidad Carlos III de Madrid, Universidad Rey Juan Carlos, Universidad a Distancia de Madrid, Universidad Antonio de Nebrija, Universidad Camilo José Cela, Universidad Europea de Madrid, Universidad Francisco de Vitoria, Universidad Pontificia Comillas y Universidad San Pablo-CEU.

5/ Jordi Xifra realizó un estudio mixto en el que se compaginaron las metodologías clásicas de la investigación en ciencias sociales con el ensayo de base teórica para conocer cómo la comunicación organizacional iba a verse afectada por la Covid-19, sobre todo en cuanto a la comunicación interna y a la responsabilidad social corporativa (RSC). Según este investigador, el virus ha puesto aún mas de manifiesto la importancia de las relaciones de confianza de los públicos con sus corporaciones.

6/ Odriozola-Chené junto a otros nueve investigadores llevaron a cabo un estudio con una marcada sensibilidad social. El trabajo está metodológicamente fundamentado en un análisis de contenido comparativo de la producción informativa de varios medios de Europa y América Latina. En su investigación se busca conocer cómo las empresas mediáticas de diversos países han enfocado el problema de la desigualdad social y económica frente al virus SARS-CoV-2. Una de las principales conclusiones advierte de que la desigualdad económica es una de las variables que más afectan a la gestión de la crisis sanitaria. 
las voces oficiales y los principales medios digitales (Costa-Sánchez; López-García, 20207). Respecto a los hábitos de consumo mediático, destacan las aportaciones centradas en examinar las consecuencias de la nueva tesitura mundial en los usos y costumbres de emisores y receptores (Masip et al., $2020^{\circ}$ ), que han sacado a relucir riesgos y problemas como las fake news o la saturación informativa.

Antes de la aparición de la Covid-19, los investigadores sociales ya habían mostrado su interés por la relevancia de los medios de comunicación de masas en el transcurso de las crisis, ya fuera desde un punto de vista político como vector estratégico en las relaciones internacionales (Marín Calahorro, 1995) o como factores de cambio de la opinión pública (Kellner, 2002 ${ }^{10}$; Martín Núñez y Montero Sierra, 2004 ${ }^{11}$ ). Dentro de la Academia, uno de los fenómenos más recurrentes con la llegada de un hito noticioso de cierta envergadura, como es el caso de la Covid-19, es la revisión y formulación de nuevas teorías para explicar la casuística de ese evento en concreto (Rodríguez-Teijeiro, 2010 ${ }^{12}$ ).

Mientras que otras crisis superadas tuvieron influencia directa en las sociedades que convivieron con ellas, el SARS-CoV-2 ha llegado a la profundidad del comportamiento humano. Si en las guerras, atentados o crisis ecológicas anteriormente comentados los autores observaron cambios sociales como consecuencia de nuevos entornos, en esta crisis sanitaria se precisan transformaciones sociales radicales a nivel global para su resolución. El sumun de este nuevo contexto cristaliza, precisamente, en el confinamiento domiciliario durante más

7/ Carmen Costa-Sánchez y Xosé López-García presentan una revisión de la política de información pública que se llevó a cabo en los primeros meses de convivencia con el virus. Para ello, relacionan la literatura académica básica sobre la resolución de conflictos y la comparan con las acciones comunicativas llevadas a cabo por la Administración y los principales medios digitales. En sus conclusiones plantean que desde el Gobierno se actuó comunicativamente con retraso y optimismo; por otro lado, también se considera que los medios fueron sensacionalistas y alarmistas.

8/ Este trabajo, llevado a cabo por un grupo de investigadores de la Universidad Ramon Llull, emplea también la encuesta para llevar a cabo un estudio de consumo de medios en diversos estratos de la población. Del mismo modo observan cómo la Covid-19 ha actuado como catalizador de alguno de los problemas más serios para el periodismo actual como la sobreabundancia informativa y las noticias falsas.

9/ Francisco Marín Calahorro vinculó en su tesis doctoral la incidencia de la comunicación social en las relaciones internacionales y la estrategia política. Para ello, realizó un amplio estudio de la información generada por estos conflictos y de la evolución de la comunicación. En particular, centró su investigación en las estrategias comunicativas de la Administración Bush en la Guerra del Golfo.

10/ Douglas Kellner, catedrático de UCLA y considerado como uno de los autores más importantes de la tercera generación de la Escuela de Fráncfort, llevó a cabo un análisis del discurso de los principales mensajes audiovisuales durante los atentados del 11 de septiembre de 2001 y llegó a la conclusión de que, desde este medio masivo, utilizando los principales recursos del lenguaje, se provocó un clima de histeria de guerra sin que se consiguiera satisfacer la función informativa de los medios.

11/ Marta Martín Núñez y Alicia Montero Sierra realizaron un original estudio en el que vincularon los hechos noticiosos más importantes descubiertos durante las horas posteriores a los atentados del 11 de marzo de 2004 con las informaciones publicadas en los distintos medios de comunicación. Aplicando esta metodología pretendían descubrir casos de manipulación informativa.

12/ Ariadna Rodríguez-Teijeiro escribió un interesante libro en el que utilizó tres teorías clásicas de la comunicación (aguja hipodérmica, efectos limitados y agenda setting) para analizar los hechos mediáticos referentes al hundimiento del buque Prestige en 2002 para proponer un cuarto modelo teórico basado en las características sociales y comunicaciones de la sociedad de la primera década del siglo XXI. 
de tres meses de un país cada vez más acostumbrado a la actividad laboral y social alejada de la vivienda. Este periodo, desde el 14 de marzo al 21 de junio de 2020, supone, por tanto, el mejor escenario temporal para una investigación de carácter social.

La condición de aislamiento domiciliario con la que se convivió durante la primera onda pandémica de este virus hubiera supuesto un nicho de oportunidad para la televisión si estuviésemos a finales del siglo xx, sin embargo, con la implantación de los medios digitales, que ya deben deshacerse de la etiqueta de «nuevos», se muestra necesario conocer cómo ha sido el consumo de información y a través de qué vía. No obstante, el nuevo paradigma digital no parece ser demasiado optimista en cuanto a las consecuencias que ha supuesto para la calidad informativa. Diversos autores han identificado y profundizado durante los últimos años precisamente en estos problemas, entre los que destacan la abundancia informativa (Crovi Druetta, 2014 ${ }^{13}$ ), las noticias falsas (Elías, 2018 ${ }^{14}$ ) o la confrontación social (Arroyas Langa y Pérez Díaz, 2016 ${ }^{15}$ ).

Este análisis, que conjuga alguno de los puntos anteriores, persigue dar un paso más allá y conocer cómo fueron percibidos los primeros contenidos sobre la Covid-19 por los estudiantes del Grado en Periodismo en Madrid, a fin de recabar los juicios y valoraciones de ese nicho de individuos, desligados del resto por sus conocimientos y su formación, sobre el llamado «periodismo de pandemia».

Se busca en definitiva determinar los aciertos y errores de los medios y periodistas en un periodo concreto y enmarcado entre el inicio del confinamiento y las primeras semanas de la «desescalada». Durante esa fase, la tarea del periodismo no se limitó a la mera actualización de datos, sino que fue contacto directo y diario con la ciudadanía; instrumento orientador sobre las recomendaciones sanitarias y guía en la lenta y progresiva vuelta a la normalidad. Su desempeño, valorado en mejor o peor término, añade, en las próximas líneas, una nueva perspectiva.

\section{Metodología}

Para la realización de esta investigación el método de análisis utilizado ha sido la encuesta de opinión anónima. El cuestionario elaborado se divide en tres sectores de acuerdo con el tipo de pregunta realizada: sociodemográficas, sobre el uso mediático y sobre la valoración del tratamiento informativo. La encuesta final se compone de 24 preguntas con un tiempo medio de cumplimentación no superior a los 15 minutos, evitando así la saturación y/o el rechazo del sujeto encuestado (Padua et al., 1987).

13/ Delia Crovi Druetta analizó el lugar que ocupaban los medios de comunicación en el proceso de generación de la incertidumbre y, pese a que en un primer momento se consideraba a la abundancia informativa como un remedio para ello, su estudio demuestra que tiende a aumentarla.

14/ Carlos Elías realizó un ensayo teórico acerca de por qué tanto los medios considerados como serios como los académicos no están actuando de forma efectiva contra las noticias falsas y cómo están provocando que los seres racionales sean cada vez menos predecibles y estén motivados por reflexiones emotivas.

15/ Enrique Arroyas Langa y Pedro Luis Pérez Díaz realizaron un estudio de la red social Twitter para analizar cómo el discurso populista de Pablo Iglesias durante las elecciones europeas de 2014 se basó en propiciar el enfrentamiento entre pueblo y poder. 
En cuanto a la tipología de las preguntas, se trata de un cuestionario integrado por preguntas cerradas con opción múltiple (19) y por preguntas abiertas (5). La razón de incluir estas últimas, al margen de las que se utilizaron para conocer la edad del encuestado y hacer una mejor clasificación demoscópica, reside en el interés por profundizar en cuestiones relativas al consumo mediático. Es decir, para obtener una relación de los medios de comunicación más consultados por los individuos.

La forma de distribución combinó varias técnicas. Por un lado, se optó por la difusión vía correo electrónico, a la que precedió un trabajo de búsqueda y recopilación de las direcciones de mail recogidas en las páginas web de las universidades españolas o en los planes docentes de las diferentes universidades, para lograr la mayor difusión entre el alumnado. Por otro, se desplegó una campaña a través de diversas plataformas de redes sociales (Twitter, Facebook, Telegram y LinkedIn). El trabajo de campo se realizó entre los días 25 de mayo de 2020, coincidiendo con el inicio de la desescalada en la Comunidad de Madrid, y el 7 de junio del mismo año. Conviene señalar que, previo paso a la distribución de la encuesta, se realizó una prueba piloto o pretest encaminado a reducir las posibles deficiencias del cuestionario. Finalmente, se ha trabajado con una muestra $\mathrm{N}=230$, garantizando un nivel de confianza superior al $94 \%$ con un error estimado del $6 \%$.

Para garantizar una mayor representatividad se llevó a cabo un sistema de muestreo aleatorio y estratificado teniendo como referencia las universidades que imparten la titulación de Periodismo en Madrid. Gracias a este procedimiento se aseguró que todas las instituciones que forman parte del universo de estudio participaran en la investigación, como se muestra en la figura 2.

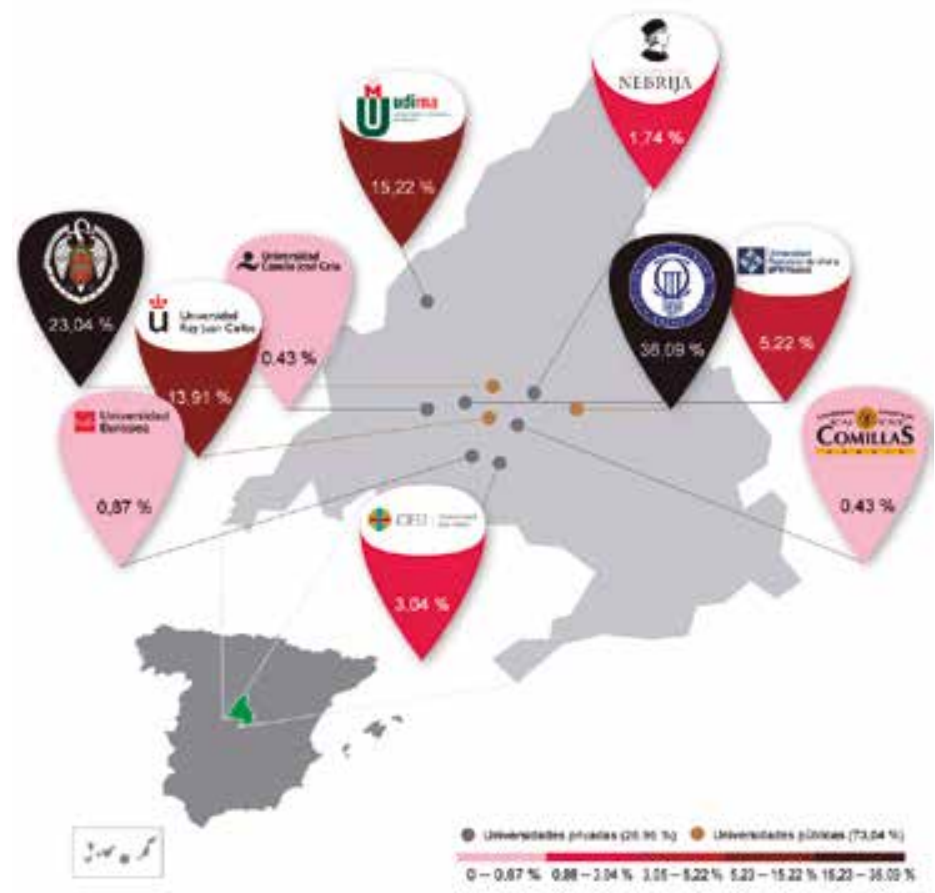

Figura 2. Estudiantes por universidades y titularidad de las mismas. Fuente: elaboración propia. 


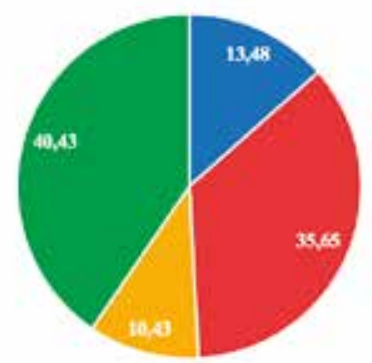

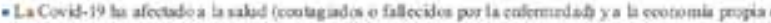

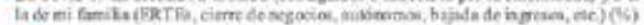

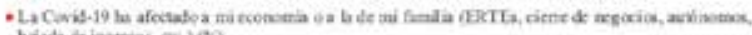

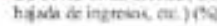

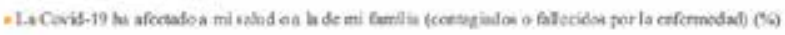

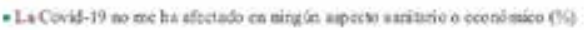

Gráfico 1. Grado de afección de la Covid-19. Fuente: elaboración propia.

En cuanto al perfil sociodemográfico de los encuestados, un porcentaje muy alto de la muestra $(95,22 \%)$ ha pasado el confinamiento en un área urbana. La mayor parte de los estudiantes se sitúan entre los 20 (23,04\%), 21 (20\%) y 22 años (14,78\%) y un $70 \%$ son mujeres, frente a un $29,13 \%$ que son hombres. Hay representación de todos los cursos académicos, habiendo una mayor presencia de cuarto $(34,78 \%)$, seguido de tercero $(29,13 \%)$, segundo $(20,43 \%)$ y primero $(13,91 \%)$. Por último, cabe señalar que al $40,43 \%$ de los estudiantes encuestados no les ha afectado la Covid-19, mientras que al porcentaje restante sí lo ha hecho en diversas formas y aspectos, tal y como se evidencia en el gráfico 1.

\section{Resultados}

\subsection{Consumo MEdiÁtico Y VÍAS de INFORMACIÓN: PREFERENCIA Y HÁBITOS DURANTE LA CRISIS}

La declaración del estado de alarma el 14 de marzo de 2020 debido a la expansión de la Covid-19 marcó un punto de inflexión en casi la totalidad de los ámbitos. En lo que respecta al consumo mediático, puede conformarse el evidente protagonismo de la televisión, que concentró a la mayor parte de la audiencia en el momento de la declaración del Estado de alarma. Casi la mitad de los encuestados, un 48,26\%, siguió este acontecimiento a través de la pequeña pantalla; una circunstancia en parte motivada por los avances informativos de las horas previas a la rueda de prensa del presidente del Gobierno, que aumentó el interés por esta comparecencia y concentró a buena parte del público en torno al televisor. Asimismo, la puesta en marcha de todas las medidas extraordinarias anunciadas por el jefe del Ejecutivo repercutió en un inmediato aumento del consumo informativo: sucedió en un $78,70 \%$ de los casos.

Ambas cuestiones, la preponderancia de la televisión y la mayor búsqueda y acceso a la información, sufrieron importantes modificaciones en las semanas siguientes, ya con la ciudadanía en estado de confinamiento. Como puede observarse (Gráfico 2), un 46,9\% de los alumnos afirmaron haber reducido su consumo de información de manera progresiva durante la crisis, frente a un $30 \%$ que lo mantuvo constante y un $23,04 \%$ que lo incrementó.

Una apreciación necesaria se encuentra en la tabla 1, la cual sostiene que el sector que mantuvo sus niveles de consumo invariables fue aquel que se vio afectado por la enfermedad del SARS-CoV-2 tanto a nivel económico, como sanitario.

En lo que respecta a la forma de acceder a los contenidos, el citado protagonismo de la televisión cedió en favor de los periódicos digitales y las redes sociales, que se convirtieron 


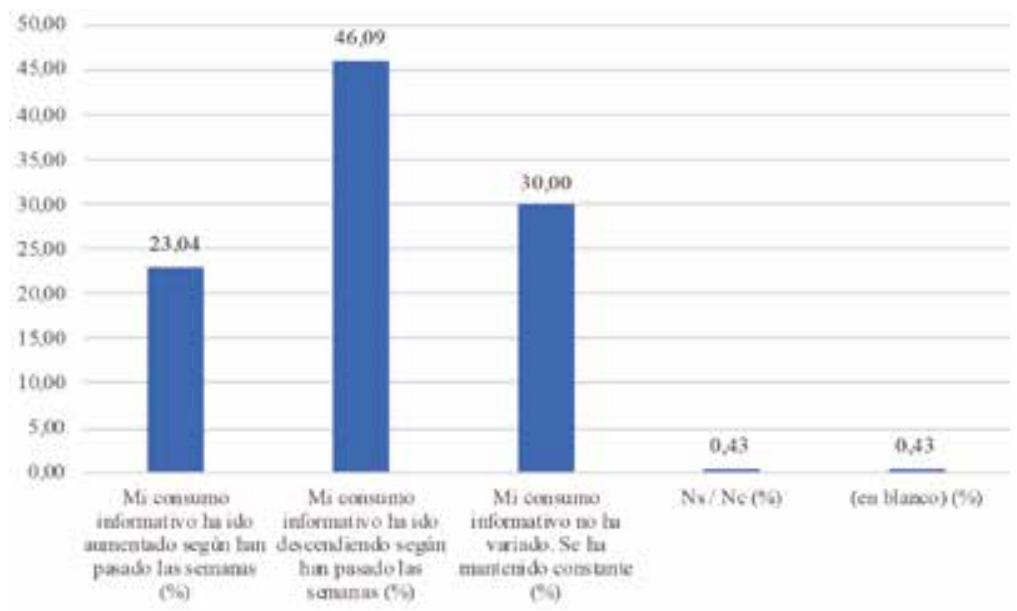

Gráfico 2. Consumo informativo a lo largo del estado de alarma. Fuente: elaboración propia.

Tabla 1. Relación entre el nivel de consumo informativo y el grado de afección por el coronavirus

\begin{tabular}{|c|c|c|c|c|c|}
\hline Grado de afección (\%) & $\begin{array}{l}\text { Mi consumo } \\
\text { informativo ha } \\
\text { ido aumentado } \\
\text { según han } \\
\text { pasado las } \\
\text { semanas }\end{array}$ & $\begin{array}{l}\text { Mi consumo } \\
\text { informativo ha } \\
\text { ido descendiendo } \\
\text { según han pasado } \\
\text { las semanas }\end{array}$ & $\begin{array}{l}\text { Mi consumo } \\
\text { informativo no } \\
\text { ha variado. Se } \\
\text { ha mantenido } \\
\text { constante }\end{array}$ & $\mathrm{Ns} / \mathrm{Nc}$ & $\begin{array}{c}\text { (en } \\
\text { blanco) }\end{array}$ \\
\hline $\begin{array}{l}\text { La Covid-19 ha afectado } \\
\text { a la salud (contagiados } \\
\text { o fallecidos por la } \\
\text { enfermedad) y a la } \\
\text { economía propia o la de } \\
\text { mi familia (ERTEs, cierre } \\
\text { de negocios, autónomos, } \\
\text { bajada de ingresos, etc.) (\%) }\end{array}$ & 16,13 & 41,94 & 41,94 & 0,00 & 0,00 \\
\hline $\begin{array}{l}\text { La Covid-19 ha afectado } \\
\text { a mi economía o a la de } \\
\text { mi familia (ERTEs, cierre } \\
\text { de negocios, autónomos, } \\
\text { bajada de ingresos, etc.) (\%) }\end{array}$ & 23,17 & 46,34 & 29,27 & 0,00 & 1,22 \\
\hline $\begin{array}{l}\text { La Covid-19 ha afectado a } \\
\text { mi salud o a la de mi familia } \\
\text { (contagiados o fallecidos } \\
\text { por la enfermedad) (\%) }\end{array}$ & 16,67 & 45,83 & 33,33 & 4,17 & 0,00 \\
\hline $\begin{array}{l}\text { La Covid-19 no me ha } \\
\text { afectado en ningún aspecto } \\
\text { sanitario o económico (\%) }\end{array}$ & 26,88 & 47,31 & 25,81 & 0,00 & 0,00 \\
\hline
\end{tabular}

Fuente: elaboración propia. 


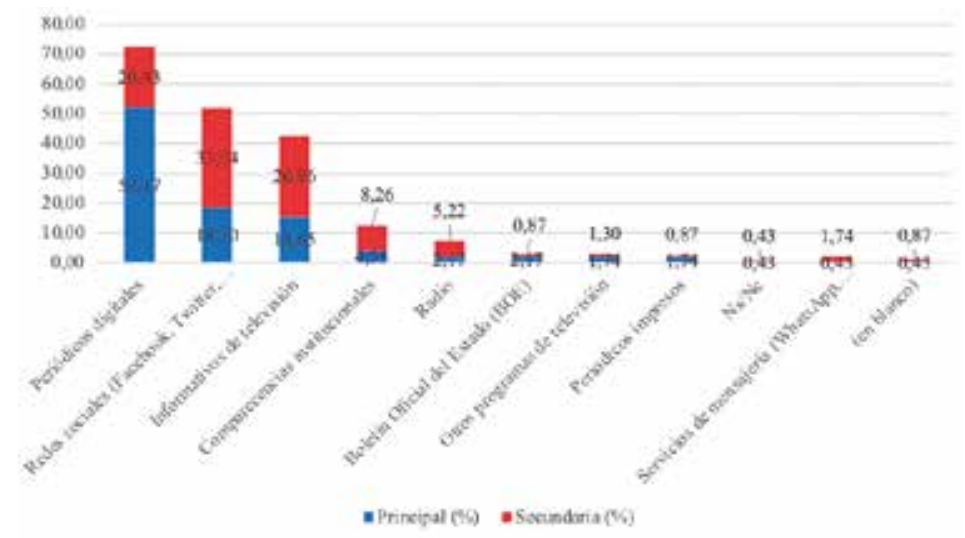

Gráfico 3. Vías de información (principales y secundarias) para informarse sobre el coronavirus. Fuente: elaboración propia.

en los instrumentos predilectos para obtener información según avanzaba la pandemia. Más en concreto, la prensa digital, con una estadística del 52,17\%, se erigió como la vía principal para informarse sobre el coronavirus, seguida de las diferentes plataformas como Twitter, Facebook o Instagram, entre otras, que computan un 33,4\%. Atendiendo a las vías secundarias, son las propias redes sociales las que se ubican en primera posición, precediendo a una televisión que perdió su impacto inicial, pero que siguió muy por encima de la radio, que acusó su carácter de escucha pasivo; la prensa escrita, clara perdedora en un entorno informativo audiovisual; o los servicios de mensajería, que siguen sin consolidarse como un canal informativo de peso, probablemente, por la relación que se establece entre estas últimas y el auge de las fake news en la era de la posverdad (Alonso González, 2019) (Gráfico 3).

En un análisis más pormenorizado, se observa que El País fue el medio de comunicación más consultado y que Twitter se impuso como la red social preferida por los usuarios. En el caso de las televisiones, Radiotelevisión Española superó a todas las cadenas privadas, de las cuales, Antena 3 fue la más visualizada. Destaca a su vez el escaso seguimiento que registra la Cadena Ser. la emisora más escuchada a nivel nacional con 3.899 oyentes diarios (EGM, 2020), y que, sin embargo, obtuvo una atención secundaria durante la pandemia (Gráfico 4).

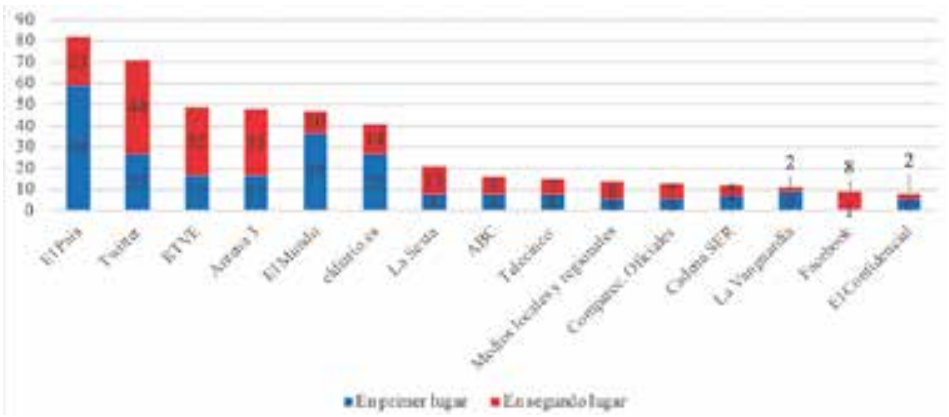

Gráfico 4. Las empresas /plataformas preferidas para informarse sobre el coronavirus. Fuente: elaboración propia. 


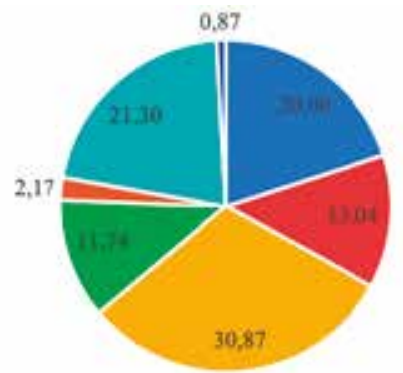

- Cada vezque tecbouna alata ca nis á spostivos electónicos (\%)

- Cirev o mós reces al da (\%)

- Eacie dos y cuate veces al dia (\%)

- Nobe consulado informacisn subre ia COVID-19 a danio (\%)

- Ns/ Ne(C)

- Itra ver al dia co

- (en blateo) (\%)

Gráfico 5. Frecuencia de consumo de la información sobre la Covid-19. Fuente: elaboración propia.

Más allá de las diferencias entre medios, los resultados de la encuesta reflejan el alto grado de seguimiento de la evolución de la enfermedad. Tan solo un 11,74\% asegura no haber consultado información a diario sobre la Covid-19, en contraposición a un $20 \%$ que lo hizo cada vez que recibió una alerta en su dispositivo electrónico y un 30,87\% cuya media estuvo entre las dos y cuatro veces al día. Además, un 13,04\% del alumnado reconoce haberse informado sobre el coronavirus al menos cinco veces al día. En total, un 85,21\% que optó por el seguimiento diario frente a una minoría que tendió a la «desconexión» (Gráfico 5).

\subsection{El periodismo a examen. Crítica y valoración sobre EL TRATAMIENTO INFORMATIVO}

El elevado índice de consumo mediático, visto en los párrafos anteriores, añade otro punto de vista cuando se suman las valoraciones respecto a la praxis y el tratamiento informativo. Tal es así, que un considerable número de encuestados, el 47,83\%, argumentó que la cantidad de información proporcionada por los medios era excesiva, mientras que un porcentaje similar, el $42,17 \%$, la consideró adecuada a su relevancia social, estableciendo una clara división de opiniones. En este punto conviene hacer una matización y establecer diferencias entre las respuestas en función del curso en el que se encontraban los sujetos encuestados.

Los alumnos de segundo y tercer curso, por ejemplo, fueron los que más anotaron la cobertura mediática desproporcionada, mientras que los de primero y cuarto (estos últimos con mayores reservas) abogaron por considerar como correcto y proporcional el tratamiento informativo. Teniendo en cuenta que la mayoría de los alumnos que desempeñaron prácticas profesionales durante la primera ola de la pandemia también entendieron que los medios estaban realizando una labor acorde con la trascendencia del momento, la tesis que puede deducirse es que el primer contacto con la actividad periodística profesional rebajó la sensación de sobreabundancia informativa, resultado de esa experiencia y de los requisitos que esta requería.

En el caso de los estudiantes de primero, la falta de un bagaje académico y de los mecanismos necesarios para juzgar las características de la labor de los medios se presentan como las causas más probables para justificar su respuesta. Se aprecia más detalladamente en las tablas 2 y 3 : 
Tabla 2. Relación entre el tratamiento cuantitativo de la información por los medios y el curso de los encuestados

\begin{tabular}{|l|c|c|c|c|c|}
\hline \multicolumn{1}{|c|}{ Curso académico de los estudiantes participantes (\%) } \\
\hline \multicolumn{1}{|c|}{ Etiquetas de fila } & $\begin{array}{c}\text { Primero } \\
(\%)\end{array}$ & $\begin{array}{c}\text { Segundo } \\
(\%)\end{array}$ & $\begin{array}{c}\text { Tercero } \\
(\%)\end{array}$ & $\begin{array}{c}\text { Cuarto } \\
(\%)\end{array}$ & $\begin{array}{c}\text { (en blanco) } \\
\text { (\%) }\end{array}$ \\
\hline $\begin{array}{l}\text { En general, los medios } \\
\text { están ofreciendo excesiva } \\
\text { información sobre la } \\
\text { Covid-19 }\end{array}$ & 37,50 & 51,06 & 50,75 & 46,25 & 75,00 \\
\hline $\begin{array}{l}\text { En general, los medios están } \\
\text { ofreciendo poca información } \\
\text { sobre la Covid-19 }\end{array}$ & 9,38 & 8,51 & 2,99 & 6,25 & 0,00 \\
\hline $\begin{array}{l}\text { En general, los medios están } \\
\text { ofreciendo una información } \\
\text { proporcional la relevancia } \\
\text { social de la Covid-19 }\end{array}$ & 43,75 & 36,17 & 41,79 & 46,25 & 25,00 \\
\hline Ns / Nc & 9,38 & 2,13 & 4,48 & 1,25 & 0,00 \\
\hline (en blanco) & 0,00 & 2,13 & 0,00 & 0,00 & 0,00 \\
\hline
\end{tabular}

Fuente: elaboración propia.

Tabla 3. Relación entre el tratamiento cuantitativo de la información por los medios y el desempeño de actividad profesional

\begin{tabular}{|l|c|c|c|}
\hline \multicolumn{1}{|c|}{} & $\begin{array}{r}\text { Desempeño de actividad profesional durante } \\
\text { el Estado de Alarma (\%) }\end{array}$ \\
\hline \multicolumn{1}{|c|}{ Etiquetas de fila } & No (\%) & Sí (\%) & (en blanco) (\%) \\
\hline $\begin{array}{l}\text { En general, los medios están ofreciendo } \\
\text { excesiva información sobre la Covid-19 }\end{array}$ & 50,78 & 33,33 & 0 \\
\hline $\begin{array}{l}\text { En general, los medios están ofreciendo } \\
\text { poca información sobre la Covid-19 }\end{array}$ & 5,18 & 11,11 & 0 \\
\hline $\begin{array}{l}\text { En general, los medios están ofreciendo } \\
\text { una información proporcional la } \\
\text { relevancia social de la Covid-19 }\end{array}$ & 41,45 & 47,22 & 0 \\
\hline Ns / Nc & 2,59 & 8,33 & 0 \\
\hline (en blanco) & 0,00 & 0,00 & 100 \\
\hline
\end{tabular}

Fuente: elaboración propia.

Otro de los aspectos para tener en cuenta en lo que respecta a la valoración del trabajo de los medios guarda relación con la credibilidad del periodismo. Ya se ha apuntado el papel 


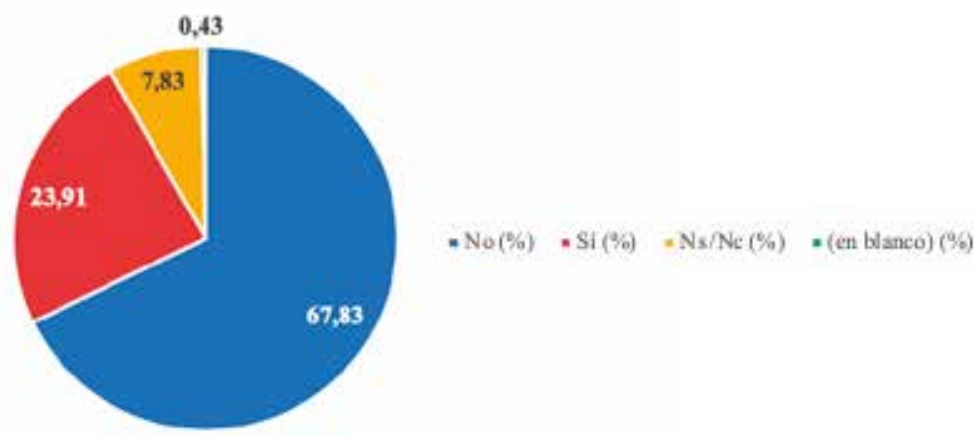

Gráfico 6. Aumento de credibilidad de los medios a raíz del estado de alarma. Fuente: elaboración propia.

de primer orden que desempeñaron los profesionales de la información, considerados como «servicios esenciales» desde el primer momento de la limitación de actividades. No obstante, sobresale que solo el $23,91 \%$ perciba un aumento de la fiabilidad de los medios a partir del Estado de alarma declarado el 14 de marzo, frente a un mayoritario 67,83\% que negó dicha circunstancia (Gráfico 6).

Una vez más, las grandes diferencias resultan de la estratificación por cursos. En este caso, la postura más crítica en cuanto al grado de confianza en la información provino del alumnado del tercer curso, pues un $73,13 \%$ de sus integrantes negó que se produjese un aumento de la credibilidad durante el desarrollo de la crisis sanitaria. En el grupo de respuestas afirmativas, los estudiantes de primer curso contabilizan el porcentaje más alto $(34,38 \%)$, seguido de los de cuarto curso (26,25\%), lo que vuelve a establecer similitudes entre ambos (Tabla 4).

De igual modo, un número ligeramente superior de los individuos que realizaron prácticas curriculares $(36,11 \%)$ frente a los que no las hicieron $(21,76 \%)$ creyó que los medios habían aumentado su credibilidad durante el confinamiento. La tónica general, en cualquier caso,

Tabla 4. Relación entre el aumento de la credibilidad de los medios y el curso de los encuestados

\begin{tabular}{|c|c|c|c|c|}
\hline \multirow[b]{2}{*}{ Curso } & \multicolumn{4}{|c|}{ Aumento de la credibilidad } \\
\hline & No & $\mathrm{Ns} / \mathrm{Nc}$ & Sí & (en blanco) \\
\hline Primero (\%) & 65,63 & 0,00 & 34,38 & 0,00 \\
\hline Segundo (\%) & 63,83 & 12,77 & 21,28 & 2,13 \\
\hline Tercero (\%) & 73,13 & 7,46 & 19,40 & 0,00 \\
\hline Cuarto (\%) & 65,00 & 8,75 & 26,25 & 0,00 \\
\hline (en blanco) (\%) & 100,00 & 0,00 & 0,00 & 0,00 \\
\hline
\end{tabular}

Fuente: elaboración propia. 
no ofrece interpretaciones muy positivas en lo que respecta a la veracidad de los contenidos informativos.

De hecho, los principales problemas que reportaron los encuestados a la hora de valorar la calidad del periodismo fueron, en primer lugar, el elevado sesgo ideológico de la información (40,87\%) y, en segundo lugar, el cariz confuso y contradictorio de las mismas $(29,57 \%)$. Únicamente un $13,4 \%$ de las respuestas valoraron la información consultada como veraz y perfectamente contrastada; porcentaje próximo al 10,97\% que denunció la escasa labor de contraste.

Para precisar aún más, cabe señalar que cuando los estudiantes ejercieron como periodistas, la ideologización/politización de los medios fue apercibida con mayor notoriedad $(64,89 \%)$, que cuando no lo hicieron (36,79\%). A su vez, el alumnado de cuarto fue quien más crítico se mostró con esta situación. Y así hizo saber en el $50 \%$ de los casos. Las semejanzas antes señaladas entre el alumnado más joven y el más experimentado no encuentra su réplica en esta parte del cuestionario, ya que los miembros de primer año fueron los que mejor valoraron las informaciones sobre el coronavirus: De ellos, el 28,13\% señaló la veracidad y la buena praxis periodística, lo cual contrasta con los porcentajes inferiores al $15 \%$ en el resto de los cursos (Tabla 5).

Tabla 5. Relación entre el sesgo y la ideologización de la información y el curso de los encuestados

\begin{tabular}{|c|c|c|c|c|c|}
\hline \multirow[b]{2}{*}{ Afirmaciones } & \multicolumn{5}{|c|}{ Curso académico de los estudiantes participantes (\%) } \\
\hline & $\begin{array}{c}\text { Primero } \\
(\%)\end{array}$ & $\begin{array}{c}\text { Segundo } \\
(\%)\end{array}$ & $\begin{array}{c}\text { Tercero } \\
(\%)\end{array}$ & $\begin{array}{c}\text { Cuarto } \\
(\%)\end{array}$ & $\begin{array}{c}\text { (en } \\
\text { blanco) } \\
(\%)\end{array}$ \\
\hline $\begin{array}{l}\text { Considero que la mayoría de } \\
\text { las informaciones carecen de } \\
\text { una buena labor de contraste }\end{array}$ & 9,38 & 10,64 & 10,45 & 12,50 & 0,00 \\
\hline $\begin{array}{l}\text { Considero que la mayoría } \\
\text { de las informaciones están } \\
\text { perfectamente contrastadas y } \\
\text { son veraces }\end{array}$ & 28,13 & 12,77 & 8,96 & 11,25 & 0,00 \\
\hline $\begin{array}{l}\text { Considero que la mayoría } \\
\text { de las informaciones están } \\
\text { sesgadas ideológicamente }\end{array}$ & 31,25 & 36,17 & 37,31 & 50,00 & 50,00 \\
\hline $\begin{array}{l}\text { Considero que muchas de ellas } \\
\text { contradicen informaciones } \\
\text { anteriores y solo generan } \\
\text { confusión }\end{array}$ & 31,25 & 29,79 & 35,82 & 22,50 & 50,00 \\
\hline $\mathrm{Ns} / \mathrm{Nc}$ & 0,00 & 8,51 & 7,46 & 3,75 & 0,00 \\
\hline (en blanco) & 0,00 & 2,13 & 0,00 & 0,00 & 0,00 \\
\hline
\end{tabular}

Fuente: elaboración propia. 
Tabla 6. Relación entre la recepción consciente de fake news y el curso de los encuestados

\begin{tabular}{|l|c|c|c|c|c|}
\hline & \multicolumn{4}{|c|}{ Curso académico de los estudiantes participantes (\%) } \\
\hline Víctima de fake news & $\begin{array}{c}\text { Primero } \\
\text { (\%) }\end{array}$ & $\begin{array}{c}\text { Segundo } \\
\text { (\%) }\end{array}$ & $\begin{array}{c}\text { Tercero } \\
(\%)\end{array}$ & $\begin{array}{c}\text { Cuarto } \\
(\%)\end{array}$ & $\begin{array}{c}\text { (en blanco) } \\
\text { (\%) }\end{array}$ \\
\hline No & 28,13 & 17,02 & 16,42 & 21,25 & 25,00 \\
\hline Ns / Nc & 6,25 & 4,26 & 1,49 & 5,00 & 0,00 \\
\hline Sí & 65,63 & 76,60 & 82,09 & 73,75 & 75,00 \\
\hline (en blanco) & 0,00 & 2,13 & 0,00 & 0,00 & 0,00 \\
\hline
\end{tabular}

Fuente: elaboración propia.

Para concluir con este bloque, el porcentaje cercano al $80 \%$ de alumnos que confesó haber recibido una fake new pone de relieve una de las grandes amenazas del periodismo actual. Las cifras ilustran que la gran mayoría de individuos afirmó ser víctima de un bulo, pese a que un porcentaje considerable de alumnos de primer curso manifestó no haber recibido fake news o, al menos, no haber sido consciente de haberlas recibido $(28,13 \%)$. Es probable que esta cifra vuelva a responder una falta de las herramientas necesarias por parte de los estudiantes con menos experiencia para determinar con precisión si una información era o no falsa (Tabla 6).

A modo de cierre, los resultados de esta encuesta permiten establecer ciertas apreciaciones en cuanto a la tipología de la información consumida antes y después de la entrada en vigor del Estado de alarma del mes de marzo de 2020 y conocer la percepción de los encuestados respecto al tipo de contenidos que deberían haber priorizado los mass media en este «periodismo de pandemia». Respecto a lo primero, el género informativo se mantuvo como el más consultado tanto en la fase previa como en la posterior al confinamiento, aunque se percibe un pequeño aumento: de un $56,09 \%$ a un $68,26 \%$. Los géneros referenciales (reportajes) y apelativos (entrevistas) descendieron del $26,96 \%$ al $13,91 \%$, al igual que la opinión, que pasó del $9,13 \%$ al $4,78 \%$ tras la fecha del 14 de marzo $^{16}$.

Por otro lado, el 56,52\% estimó que la información acerca de las estadísticas diarias de cara a conocer la evolución del estado del virus, así como la actualidad desde el punto de vista sanitario, tendría que haber sido la predominante en los diferentes medios de comunicación. El aprendizaje sobre el lavado de manos y las medidas de seguridad ocupa la segunda posición $(27,83 \%)$, con cifras muy superiores al resto de opciones, como la información sobre las distintas fases de la «desescalada» $(5,65 \%)$, las iniciativas solidarias $(2,17 \%)$ o las historias de superación personal $(5,22 \%)$

Al interrogante sobre qué tipo de información deberían haber priorizado los medios en segundo lugar, el aprendizaje sobre el lavado de manos, con un $28,6 \%$, se coloca en primera posición. En segundo término, aparecen de nuevo las estadísticas diarias y los contenidos sanitarios $(22,61 \%)$, reflejo de que las llamadas soft news, por lo general más relacionadas

16/ Se ha utilizado la tipología de géneros periodísticos que realizó Mariano Cebrián Herreros (2000). 


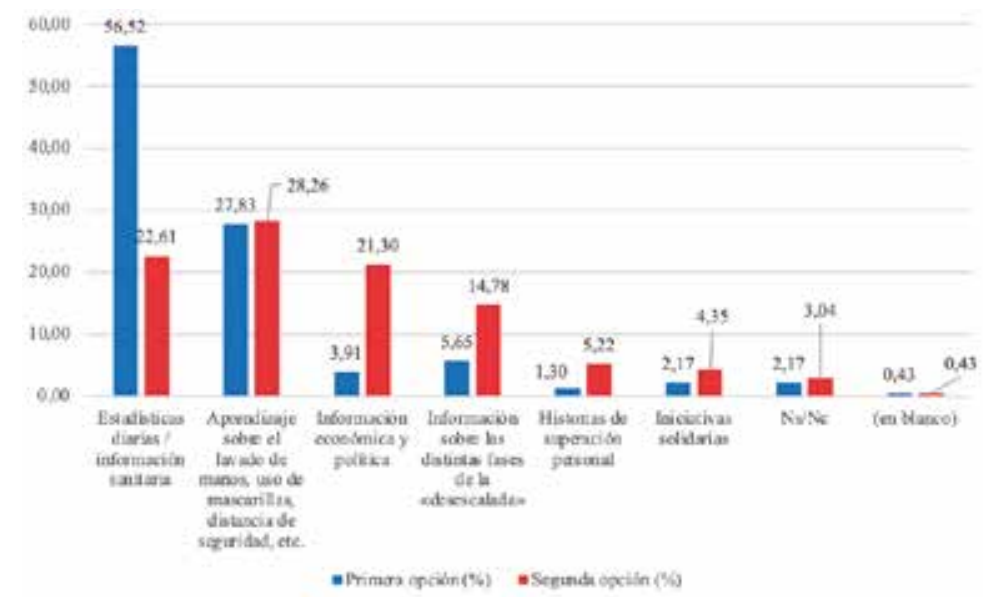

Gráfico 7. Tipo de información que deberían haber priorizado los medios en primer y segundo lugar. Fuente: elaboración propia.

con el entretenimiento o la dispersión, se consideraron mucho menos esenciales que la información pura o hard news en el escenario marcado por el coronavirus (Gráfico 7).

\section{Conclusiones/Discusión}

El anuncio de la entrada en vigor del Estado de alarma el 14 de marzo de 2020 se ha convertido en uno de los hitos mediáticos referentes durante el desarrollo de la pandemia de la Covid-19 en España. La televisión, como en otros momentos de la Historia, se instaló como la ventana principal a través de la cual los futuros periodistas siguieron este acontecimiento en directo. En estas horas previas al confinamiento la pequeña pantalla volvía a ser considerada como el medio más influyente y, además, la nueva situación de aislamiento en los hogares acercaba en mayor medida la televisión a los estudiantes de periodismo de Madrid. Sin embargo, el seguimiento diario durante la primera onda pandémica se realizó por el canal digital. Los estudiantes de periodismo de Madrid mostraron un mayor interés hacia los medios online y redes sociales dejando claro que ni en las condiciones óptimas para el desarrollo televisivo se consigue hacer frente a la avalancha digital y que el futuro de la profesión apunta a centrar todos sus esfuerzos en estos nuevos formatos. Queda por tanto refutada la subhipótesis primera.

La recepción informativa durante estos primeros meses de pandemia no ha sido constante ni lineal para los estudiantes de periodismo. Los primeros días, en los que las cifras de muertos e infectados no paraban de multiplicarse y en los que la preocupación social generalizada se elevó a niveles inéditos, afectaron directamente a las necesidades de los futuros profesionales de la información. Sin embargo, cuando la curva comenzó a aplanarse, se empezó a ver un descenso y una estabilización en el consumo de información por parte de los encuestados. Además de una preocupación por la situación general, los estudiantes variaron su uso informativo en base a su casuística personal. Muchos vieron cómo la salud familiar, o su propia economía, sufría por esta crisis y eso afectó a su relación con la información. En concreto, aquellos que vivieron una infección o muerte en su núcleo más cercano 
mantuvieron, en mayor proporción al resto, un nivel informativo constante durante la etapa del confinamiento, tal y como se contemplaba en la primera hipótesis. Cabe proponer en este punto una interesante vía de estudio futuro que analice cómo los problemas de salud están asociados a un mayor grado de consumo de información.

Pese a que los estudiantes de periodismo de la Comunidad de Madrid se han centrado mayoritariamente durante los meses de estudio en los nuevos medios digitales y en las plataformas de las redes sociales, ellos mismos son muy críticos con el papel que su futura profesión ha tenido. En términos generales, están preocupados por el concepto de la infodemia; por la pérdida de credibilidad durante la Covid-19; por el sesgo ideológico; la confusión que genera el periodismo y las fake news. En todos los cursos son sensibles a estos problemas generales y además todos consideran que han empeorado durante esta crisis. Sin embargo, la adquisición de conocimientos y el acercamiento a la actividad profesional ha provocado variaciones entre cursos. En la segunda hipótesis de este trabajo se planteaba que el grado de familiarización con la profesión era un vector clave en el aumento de las perspectivas críticas. Sin embargo, no ha sido así. Los alumnos de segundo y tercero son los que más se han preocupado por la sobreinformación y la credibilidad, mientras que los de cuarto y los que han realizado prácticas han sido los que más han asimilado la carga ideológica de la información. Pese a que los datos de las encuestas refuten claramente esta hipótesis, se puede inferir el porqué de este asunto. Los alumnos de cuarto ven muy cerca su salida al mundo profesional, muchos de ellos ya ejercen el periodismo desde prácticas académicas, por tanto, es comprensible que no consideren que haya demasiada información y de poca credibilidad, puesto que iría contra su propio desempeño de una forma directa. En cambio, sí que se han mostrado inquietos en cuanto a la ideologización. Cabe reseñar que la línea editorial no la marcan las jóvenes promesas de los medios y que estos alumnos han podido observarlo directamente en sus primeras experiencias periodísticas.

Con el caso de las noticias falsas ha ocurrido algo similar. Los alumnos de primer y último curso han sido los que menos consideran que hayan sido víctimas, por tanto, sí que se puede confirmar la subhipótesis dos, pero sería necesario puntualizar que se ha observado que esa impermeabilidad sobre las fake news en los más jóvenes puede deberse a un desconocimiento de ellas, no a una labor efectiva de comprobación. Caso contrario a lo que ocurriría con los de último curso.

Este estudio demuestra, una vez más, que la consolidación del medio digital supone el desplazamiento casi total de los medios clásicos. Sin embargo, es novedoso conocer que esto no ocurra tan solo en los nuevos consumidores de información sino también en los propios creadores, los cuales presumían de mantener un mayor romanticismo por el papel, la radio o la televisión. En lugar de eso, las empresas tradicionales de información se han visto rebasadas en términos de audiencia por plataformas que no necesariamente parten con una función exclusivamente informativa, como puede ser Twitter. Este hecho, lejos de ser anecdótico, debe afectar a la generación de ruido en el canal informativo y debería ser explorado en futuras investigaciones.

Otro punto concluyente de este artículo debe referirse a la cantidad de información que recibe la audiencia. Si bien es cierto que en los primeros días de la pandemia en España la ratio de la información recibida/emitida se adaptó a las particularidades del momento, la pérdida del carácter novedoso de la información sobre la Covid-19 junto a la mejora de los datos epidemiológicos provocó que el consumo comenzara a descender mientras que los medios no variaron 
su ritmo de producción de piezas periodísticas. Además, esta tendencia se presupone que será aún mayor en grupos sociales con una menor sensibilidad a la información, no como el que aquí se ha estudiado. Aunque este estudio no tiene como fin principal explorar cómo deben ser los flujos de información, parece claro afirmar que el medio digital, por su propia idiosincrasia, no tiene tanta «flexibilidad» como tienen los medios de masas precedentes, para nivelar la importancia de un hecho noticioso en base al número de piezas publicadas. Este hecho, por tanto, supondría un problema para las investigaciones de la opinión pública que se basan solo en el análisis de medios de comunicación social de carácter digital. También, como demuestra el artículo, esta rigidez para cambiar el ritmo informativo puede ser la causante principal de la sobreabundancia informativa detectada por usuarios e investigadores.

Una de las cuestiones que ha dejado sobre la mesa esta investigación y que también debería ser explorada en futuras aproximaciones al tema de estudio está relacionada con la importancia de las emociones en relación con el consumo. Los datos obtenidos marcan una clara tendencia por la cual aquellas personas afectadas sensiblemente por esta enfermedad son aquellas que más piezas periodísticas han asumido. Aunque la cercanía con la noticia afecte a la necesidad de información, la capacidad objetiva de análisis de los mensajes puede verse también alterada, algo que podría ser un caldo de cultivo para el éxito de los mensajes populistas de confrontación con el poder.

En definitiva, este estudio ha clarificado cómo los estudiantes de la Comunidad de Madrid han observado el desarrollo del periodismo en un delicado contexto. Además de hacerlo a través de las pantallas de sus ordenadores y smartphones, han demostrado una postura altamente crítica con la labor mediática. Pese a que estos resultados pueden resultar alarmantes, no hay que olvidar que portan un gran valor. $Y$ es que son los futuros profesionales de la información los que marcan las pautas que debe seguir el periodismo de pandemia, el cual debe desplegar, más que nunca, su labor como agente social dentro del abundante «ruido informativo» que se respira en Internet.

\section{Bibliografía}

ALONSO GONZÁLEZ, Marián (2019). «Fake news: desinformación en la era de la sociedad de la información». Ámbitos. Revista Internacional de Comunicación, (45), 29-52. DOI: 10.12795/ Ambitos.2019.i45.03

ARROYAS LANGA, Enrique y PÉREZ DÍAZ, Pedro Luis (2015). «La nueva narrativa identitaria del populismo: un análisis del discurso de Pablo Iglesias (Podemos) en Twitter». Cultura, Lenguaje y Representación, 15, 51-63. DOI: 10.6035/clr.2016.15.4

CASERO-RIPOLLÉS, Andreu (2020). «Impact of Covid-19 on the media system. Communicative and democratic consequences of news consumption during the outbreak». El profesional de la información, 29(2), e290223. DOI: 10.3145/epi.2020.mar.23

CEBRIÁN HERREROS, Mariano (2000). Géneros informativos audiovisuales. México D.F.: ILCE. ISBN: 9789685247115.

CIS (2020). Barómetro especial de abril 2020. Estudio n. 3.279. Centro de Investigaciones Sociológicas. Recuperado de http://www.cis.es/cis/export/sites/default/-Archivos/Marginales/3260_3279/3279/ es3279mar.pdf 
COSTA-SÁNCHEZ, Carmen y LÓPEZ-GARCÍA, Xosé (2020). «Comunicación y crisis del coronavirus en España. Primeras lecciones». El profesional de la información, 29(3), e290304. DOI: 10.3145/ epi.2020.may.04

CROVI DRUETTA, Delia (2014). “¿Es la abundancia informativa una respuesta a la incertidumbre?». Revista Internacional de Comunicación y Desarrollo, 1, 103-113. Recuperado de https://revistas. usc.gal/index.php/ricd/article/view/1991

ELÍAS, Carlos (2018). «Fakenews, poder y periodismo en la era de la posverdad y hechos alternativos». Ámbitos: Revista internacional de comunicación, (40), 1139-1979. Recuperado de https://hdl. handle.net/11441/71888

EGM (2020). Estudio General de Medios. Realizado entre el 8 de enero y 17 de marzo de 2020. Recuperado de http://reporting.aimc.es/index.html\#/main/cockpit

HABERMAS, Jürgen (2006). «Political communication in media society: Does democracy still enjoy an epistemic dimension? The impact of normative theory on empirical research». Communication theory, 16(4), 411-426. DOI: 10.1111/j.1468-2885.2006.00280.x

KELLNER, Douglas (2002). "Información, guerra y terrorismo: el 11 de septiembre. Medios de comunicación y fiebre de guerra». Signo y pensamiento, 21(40), 9-18. Recuperado de https:// dialnet.unirioja.es/servlet/articulo?codigo $=2845787$ \&orden $=0$ \&info=link

KOVACH, Bill y ROSENSTIEL, Tom (2007). The elements of journalism: What news people should know and the public should expect. New York: Three Rivers Press. ISBN: 9780307346704.

LÁZARO-RODRÍGUEZ, Pedro y HERRERA-VIEDMA, Enrique (2020). «Noticias sobre Covid-19 y 2019nCoV en medios de comunicación de España: el papel de los medios digitales en tiempos de confinamiento». El profesional de la información, 29(3), e290302. DOI:10.3145/epi.2020.may.02

MARÍN-CALAHORRO, Francisco (1995). Comunicación social y situaciones de crisis internacionales. Tesis doctoral. Madrid: Universidad Complutense de Madrid.

MARTÍN NÚÑEZ, Marta y MONTERO SIERRA, Alicia (2004). «La manipulación en los medios de comunicación. Tratamiento informativo del 11M». Fòrum de Recerca, 10. Recuperado de http:// repositori.uji.es/xmlui/bitstream/handle/10234/79010/forum_2004_27.pdf?sequence=1

MASIP, Pere, ARAN-RAMSPOTT, Sue, RUIZ-CABALLERO, Carlos, SUAU, Jaume, ALMENAR, Ester y PUERTAS-GRAELL, David (2020). "Consumo informativo y cobertura mediática durante el confinamiento por el Covid-19: sobreinformación, sesgo ideológico y sensacionalismo». El profesional de la información, 29(3), e290312. DOI: 10.3145/epi.2020.may.12

MINISTERIO DE CIENCIA, INNOVACIÓN Y UNIVERSIDADES (2019). Sistema Integrado de Información Universitaria (SIIU). Estadísticas de Educación EDUCAbase. Secretaría General de Universidades. Recuperado de: http://estadisticas.mecd.gob.es/EducaDynPx/educabase/index. htm?type=pcaxis\&path=/Universitaria/Alumnado/1GradoCiclo/Matriculados/\&file=pcaxis\#

MINISTERIO DE SANIDAD (2020). Enfermedad por el coronavirus (Covid-19). Actualización número 155, de 3 de julio. Recuperado de https://www.mscbs.gob.es/profesionales/saludPublica/ccayes/ alertasActual/nCov-China/documentos/Actualizacion_155_COVID-19.pdf

ODRIOZOLA-CHÉNÉ, Javier, DÍAZ-NOCI, Javier, SERRANO-TELLERÍA, Ana, PÉREZ-AROZAMENA, Rosa, PÉREZ-ALTABLE, LINARES-LANZMAN, Juan, GARCíA-CARRETERO, Lucía, CALVORUBIO, Luis-Mauricio, TORRES-MENDOZA, Manuel y ANTÓN-BRAVO, Adolfo (2020). «Inequality in times of pandemics: How online media are starting to treat the economic consequences of the coronavirus crisis".

PADUA, Jorge, AHMAN, Ingvar, APEZECHEA, Héctor y BORSOTTI, Carlos (1987). Técnicas de investigación aplicadas a las ciencias sociales. Madrid: Esfera de los libros. ISBN: 9789681602888. 
POLLÁN, Marina, PÉREZ-GÓMEZ, Beatriz, PASTOR-BARRIUSO, Roberto, OTEO, Jesús, HERNÁN, Miguel A., PÉREZ-OLMEDA, Mayte ... y YOTTI, Raquel (2020). «Prevalence of SARS-CoV-2 in Spain (ENE-COVID): A nationwide, population-based seroepidemiological study. The Lancet 396(10250), 535-544. DOI: 10.1016/S0140-6736(20)31483-5

RODRÍGUEZ-TEIJEIRO, Ariadna (2010). El Prestige como hiper-realidad mediática. Poder y efectos de los medios de comunicación en la construcción de la realidad social. A Coruña: Universidade da Coruña. ISBN: 978-84-9749-423-6.

XIFRA, Jordi (2020). «Comunicación corporativa, relaciones públicas y gestión del riesgo reputacional en tiempos del Covid-19». El profesional de la información, 29(2), e290220. DOI: 10.3145/epi.2020. mar.20 